\title{
Some results for common fixed point on $\varphi$-contractions in k-partially ordered fuzzy metric space
}

Jiaming Jin, Chuanxi Zhu*, Zhaoqi Wu, Haochen Wu

Department of Mathematics, Nanchang University, Nanchang, 330031, P. R. China.

Communicated by R. Saadati

\begin{abstract}
The notion of coincidence point and common fixed point were extended in generalized partially ordered fuzzy metric spaces. Under some conditions, some coincidence point and common fixed point theorems were established in generalized partially fuzzy metric spaces using weakly compatible mappings. These results improve some theorems in corresponding literature. (c)2017 All rights reserved.
\end{abstract}

Keywords: Fuzzy metric space, weakly compatible mappings, common fixed point, k-partially ordered. 2010 MSC: 54A40, 54H25.

\section{Introduction}

In 1987, Guo and Lakshmikantham [7] introduced the notion of coupled fixed point. Recently, GnanaBhaskar and Lakshmikantham [5] established some coupled fixed point theorems in partially ordered metric space. Sedghi et al. [18] studied coupled fixed point in fuzzy metric space. After that, common coupled fixed point results for compatible mappings in partially ordered fuzzy metric spaces were established by $\mathrm{Hu}$ [8] and $\mathrm{Hu}$ et al. [9]. Very recently, coupled coincidence point and fixed point results for compatible mappings was established in partially ordered fuzzy metric spaces by Chouldhury et al. [1]. And, Roldan et al. [15] obtained multidimensional coincidence point theorems for nonlinear mappings in any number of variables in partially ordered fuzzy metric spaces. Later, Wang [20] obtained some common fixed point and coincidence point results for weakly compatible mappings in partially ordered fuzzy metric spaces.

Ćirić [2] introduced the condition:

(a) $\phi(0)=0, \phi(t)<t$ and $\liminf _{r \rightarrow t^{+}} \phi(t)<t$ for all $t>0$.

Later, Jachymski [10] presented the condition:

(b) $0<\phi(t)<t$ and $\lim _{n \rightarrow \infty} \phi^{n}(t)=0$ for all $t>0$.

\footnotetext{
*Corresponding author

Email addresses: jiamingjin123@163.com (Jiaming Jin), chuanxizhu@126.com (Chuanxi Zhu)
} 
Fang [3] introduced the condition:

(c) for each $t>0$ there exists $r \geqslant t$ such that $\lim _{n \rightarrow \infty} \phi^{n}(r)=0$ in the context of Menger probabilistic metric spaces and fuzzy metric spaces.

Recently, Jin et al. [11] introduced the condition:

(d) for each $t>0$ there exist $r>t$ and $N \in \mathbb{N}$ such that $\phi^{n}(r)<t$ for all $n>\mathbb{N}$.

In this paper, we extend the notion of $\Upsilon$-coincidence point, coincidence and common fixed point and etc. Under the condition (d), we present some multidimensional coincidence point and common fixed point results for weakly compatible mappings in generalized partially ordered fuzzy metric spaces.

\section{Preliminaries}

In order to state our main results, we recall the following notions. Let $n \in \mathbb{N}, X$ be a non-empty set and $X^{n}$ be the Cartesian product of $n$ copies of $X$. For brevity, $\left(y_{1}, y_{2}, \cdots, y_{n}\right),\left(y_{m}^{1}, y_{m}^{2}, \cdots, y_{m}^{n}\right)$, $\left(z_{m}^{1}, z_{m}^{2}, \cdots, z_{m}^{n}\right),\left(z_{1}, z_{2}, \cdots, z_{n}\right),\left(v_{1}, v_{2}, \cdots, v_{n}\right)$ and $\left(x_{0}^{1}, x_{0}^{2}, \cdots, x_{0}^{n}\right)$ will be denoted by $Y, Y_{m}, Z_{m}, Z, V$ and $\mathrm{X}_{0}$, respectively.

Throughout this paper, let $\{A, B\}$ be a partition of the set $\Lambda_{n}=(1,2, \cdots, n)$, i.e., $A \cup B=\Lambda_{n}$ and $A \cap B=\emptyset$. Let $\sigma_{1}, \sigma_{2}, \cdots, \sigma_{l}: \Lambda_{n} \rightarrow \Lambda_{n}$ be $n$ mappings from $\Lambda_{n}$ into itself. We denote

$$
\begin{aligned}
& \Omega_{A, B}=\left\{\sigma: \Lambda_{n} \rightarrow \Lambda_{n} \mid \sigma(A) \subseteq A \text { and } \sigma(B) \subseteq B\right\}, \\
& \Omega_{A, B}^{\prime}=\left\{\sigma: \Lambda_{n} \rightarrow \Lambda_{n} \mid \sigma(A) \subseteq B \text { and } \sigma(B) \subseteq A\right\},
\end{aligned}
$$

$\mathbb{N}=\{0,1, \cdots, n, \cdots\}, \mathbb{N}^{+}=\{1,2, \cdots, n, \cdots\}, \mathbb{R}^{+}=[0, \infty)$, and $\mathbb{I}=[0,1]$. If $(X, \preceq)$ is a partially ordered metric space, it is easy to know that $\left(X^{n}, \preceq\right)$ is a partially ordered metric space when $a_{i} \preceq b_{i}$ for $\left(a_{1}, \cdots, a_{n}\right),\left(b_{1}, \cdots, b_{n}\right) \in X^{n}$ and $i \in\{1,2, \cdots, n\}$. We use the following notation from [14], for $y, v \in X$ and $i \in \Lambda_{n}$

$$
y \preceq_{i} v \Leftrightarrow\left\{\begin{array}{l}
y \preceq v, \text { if } i \in A, \\
y \succeq v, \text { if } i \in B .
\end{array}\right.
$$

Consider on $X^{n}$ the next natural k-partial order: for $Y, V \in X^{n}$

$$
\mathrm{Y} \preceq_{l} V \Leftrightarrow\left(y_{i k+1}, \cdots, y_{i k+k}\right) \preceq_{i+1}\left(v_{i k+1}, \cdots, v_{i k+k}\right) \Leftrightarrow y_{i k+s} \preceq_{i+1} v_{i k+s},
$$

for $i \in\{0, \cdots, l-1\}, s \in\{1, \cdots, k\}$ and $l=\frac{n}{k} \in \mathbb{N}$. If $Y \preceq_{l} V$ or $Y \succeq_{l} V$, then two points $Y$ and $V$ are comparable (denoted by $\mathrm{Y} \asymp_{l} \mathrm{~V}$ ). It has been considered by Wang [19] for $k=1$.

Definition 2.1. Let $\left(X^{n}, \preceq_{l}\right)$ be a $k$-partially ordered set for $k=\frac{n}{l} \in \mathbb{N}$, and $T, G$ are self-mappings of $X^{n}$. It is said that $T$ is a $G_{k}$-isotone mapping, if for any $Y_{1}, Y_{2} \in X^{n}$,

$$
\mathrm{G}\left(\mathrm{Y}_{1}\right) \preceq_{\mathrm{l}} \mathrm{G}\left(\mathrm{Y}_{2}\right) \Rightarrow \mathrm{T}\left(\mathrm{Y}_{1}\right) \preceq_{\mathrm{l}} \mathrm{T}\left(\mathrm{Y}_{2}\right) .
$$

Definition 2.1 is equivalent to [19, Definition 3.2] for $k=1$.

Definition 2.2. Let $\left(X^{n}, \preceq\right)$ be a partially ordered space, and $F: X^{n} \rightarrow X^{k}$ and $G: X^{k} \rightarrow X^{k}$ are two mappings. We say that $F$ has the mixed $g_{k}$-monotone property, if $F$ is $g_{k}$-monotone non-decreasing in arguments of $A$ and $g_{k}$-monotone non-increasing in arguments of $B$, i.e., for $x_{1}, x_{2}, \cdots, x_{n}, y_{1}, \cdots, y_{k}$, $z_{1}, \cdots, z_{k} \in X$ and $i \in\{0, \cdots, l-1\}$ where $l=\frac{n}{k}$,

$$
\begin{aligned}
g\left(y_{1}, \cdots, y_{k}\right) \preceq g\left(z_{1}, \cdots, z_{k}\right) \Rightarrow & F\left(x_{1}, \cdots, x_{i k}, y_{1}, \cdots y_{k}, x_{i k+k+1}, \cdots, x_{n}\right) \\
& \preceq_{i+1} F\left(x_{1}, \cdots, x_{i k}, z_{1}, \cdots, z_{k}, x_{i k+k+1}, \cdots, x_{n}\right) .
\end{aligned}
$$

Definition 2.2 is equivalent to [14, Definition 5] for $k=1$. 
Definition 2.3 ([19]). An element $Y \in X^{n}$ is called a coincidence point of the mappings $T: X^{n} \rightarrow X^{n}$ and $G: X^{n} \rightarrow X^{n}$ if $T(Y)=G(Y)$. Furthermore, if $T(Y)=G(Y)=Y$, then we say that $Y$ is a common fixed point of $T$ and $G$.

Definition 2.4. Let $F: X^{n} \rightarrow X^{k}$ and $g: X^{k} \rightarrow X^{k}$ be two mappings where $l=\frac{n}{k} \in \mathbb{N}$. A point $\left(x_{1}, x_{2}, \cdots, x_{n}\right) \in X^{n}$ is a $\Upsilon_{k}$-coincidence point of $F$ and $g$, if

$$
F\left(x_{\sigma_{i}(1)}, x_{\sigma_{i}(2)}, \cdots, x_{\sigma_{i}(n)}\right)=g\left(x_{i k+1}, x_{i k+2}, \cdots, x_{i k+k}\right),
$$

for $i \in\{0,1, \cdots, l-1\}$.

Definition 2.4 is equivalent to [12, Definition 5] for $k=1$.

Definition 2.5. A triple $\left(X^{k}, \tau_{M^{k}}, \preceq\right)$ is called a partially ordered topological space, if $\tau_{M^{k}}$ is a Hausdorff topology on $X^{k}$ and $\preceq$ is partial order on $X^{k}$. g is a self-mapping on $X^{k}$. A partially ordered topological space $\left(X^{k}, \tau_{M^{k}}, \preceq\right)$ is said to have the sequential $g_{k}$-monotone property, if it verifies:

(i) If $\left\{\left(x_{m}^{1}, \cdots, x_{m}^{k}\right)\right\}$ is a non-decreasing sequence and $\left\{\left(x_{m}^{1}, \cdots, x_{m}^{k}\right)\right\} \rightarrow\left(x_{1}, \cdots, x_{k}\right)$, then

$$
g\left(x_{m}^{1}, x_{m}^{2}, \cdots, x_{m}^{k}\right) \preceq g\left(x_{1}, \cdots, x_{k}\right), \quad \text { for } m \in \mathbb{N}^{+} .
$$

(ii) If $\left\{y_{m}^{1}, \cdots, y_{m}^{k}\right\}$ is a non-increasing sequence and $\left\{y_{m}^{1}, \cdots, y_{m}^{k}\right\} \rightarrow\left(y_{1}, \cdots, y_{k}\right)$, then

$$
g\left(y_{m}^{1}, y_{m}^{2}, \cdots, y_{m}^{k}\right) \succeq g\left(y_{1}, \cdots, y_{k}\right), \quad \text { for } m \in \mathbb{N}^{+} .
$$

If $g$ is the identity mapping, then $X^{k}$ is said to have the sequential monotone property. It is easy to see that Definition 2.5 is equivalent to [20, Definition 2.7] for $k=1$.

Definition 2.6 ([17]). A triangular norm is a map $*: \mathbb{I} \times \mathbb{I} \rightarrow \mathbb{I}$ that is associative, commutative, nondecreasing in both arguments and has 1 as identity. A t-norm is continuous if it is continuous in $\mathbb{I}^{2}$ as mapping. If $a_{1}, a_{2}, \cdots, a_{m} \in \mathbb{I}$, then

$$
*_{i=1}^{m} a_{i}=a_{1} * a_{2} * \cdots * a_{m} .
$$

For each $a \in[0,1]$, the sequence $\left\{*^{m} a\right\}_{i=1}^{\infty}$ is defined inductively by $*^{1} a=a$ and $*^{m+1} a=\left(*^{m} a\right) * a$ for all $m \geqslant 1$.

Definition 2.7 ([13]). Let $(X, M, *)$ be a fuzzy metric spaces (for short, FMS), if $X$ is an arbitrary non-empty set, $*$ is a continuous t-norm, $M: X \times X \times \mathbb{R} \rightarrow \mathbb{I}$, where $M: X \times X \times \mathbb{R}^{+} \rightarrow \mathbb{I}$ is a fuzzy set, satisfying for $x, y, z \in X$ and $t, s>0$,

$$
\begin{aligned}
& (F M-1) M(x, y, 0)=0 \text { and } M(x, y, t)>0 ; \\
& (F M-2) M(x, y, t)=1 \text {, if and only if } x=y ; \\
& (F M-3) M(x, y, t)=M(y, x, t) ; \\
& (F M-4) M(x, z, t+s) \geqslant M(x, y, t) * M(y, z, s) ; \\
& (F M-5) M(x, y, \cdot): \mathbb{R}^{+} \rightarrow \mathbb{I} \text { is left continuous for } i=1, \cdots, n .
\end{aligned}
$$

Definition 2.8. Let $\left(X^{n}, M^{n}, *, \preceq_{l}\right)$ be a k-partially ordered fuzzy metric spaces (for short, k-poFMS), if $X$ is an arbitrary non-empty set, $*$ is a continuous t-norm, $M^{n}: X^{n} \times X^{n} \times \mathbb{R} \rightarrow \mathbb{I}$ is a mapping defined by $M^{n}=*_{i=1}^{n} M\left(x_{i}, y_{i}, t\right)$ where $M: X \times X \times \mathbb{R}^{+} \rightarrow \mathbb{I}$ is a fuzzy set, and $\preceq_{l}$ is a k-partial order on $X^{n}$, satisfying for $x=\left(x_{1}, \cdots, x_{n}\right), y=\left(y_{1}, \cdots, y_{n}\right), z=\left(z_{1}, \cdots, z_{n}\right) \in X^{n}$ and $t, s>0$, 
$(P O F-1) M^{n}(x, y, 0)=0$ and $M^{n}(x, y, t)>0$;

$(P O F-2) M^{n}(x, y, t)=1$, if and only if $x=y$;

$(P O F-3) M^{n}(x, y, t)=M^{n}(y, x, t)$;

$(P O F-4) M^{n}(x, z, t+s) \geqslant M^{n}(x, y, t) * M^{n}(y, z, s) ;$

$(\mathrm{POF}-5) \mathrm{M}^{\mathrm{n}}(x, y, \cdot): \mathbb{R}^{+} \rightarrow \mathbb{I}$ is left continuous for $i=1, \cdots, \mathrm{n}$.

Definition 2.8 is equivalent to [4, Definition 2.15], for $n=1$.

Definition 2.9. Let $\left(X^{n}, M^{n}, *, \preceq_{l}\right)$ be a k-poFMS for $l=\frac{n}{k}$. A sequence $\left\{\left(x_{m}^{1}, \cdots, x_{m}^{n}\right)\right\}$ in $X^{n}$ is said to be convergent to $\left(x_{1}, \cdots, x_{n}\right) \in X$, if $\lim _{m \rightarrow \infty} *_{i=1}^{n} M\left(x_{m}^{n}, x_{n}, t\right)=1$ for $t>0$. A sequence $\left\{\left(x_{m}^{1}, \cdots, x_{m}^{n}\right)\right\}$ in $X^{n}$ is said to a Cauchy sequence, if for $\varepsilon \in(0,1)$ and $t>0$, there exists $n_{0} \in \mathbb{N}$, such that $*_{i=1}^{n} M\left(x_{p}^{i}, x_{q}^{i}, t\right)>$ $1-\varepsilon$ for $p, q \geqslant n_{0}$. A k-poFMS is called complete, if every Cauchy sequence is convergent in $X^{n}$.

Definition 2.10. Let $\left(X^{n}, M^{n}, *, \preceq_{l}\right)$ be a k-poFMS for $l=\frac{n}{k}$. A mapping $G: X^{n} \rightarrow X^{k}$ is said to be continuous at a point $Y_{0} \in X^{n}$, if for any sequence $\left\{Y_{m}\right\}_{m} \geqslant 0$ in $X^{n}$ converging to $Y_{0}$, the sequence $\left\{G\left(Y_{m}\right)\right\}_{m \geqslant 0}$ converges to $G\left(Y_{0}\right)$. If $G$ is continuous at each $Y_{0} \in X^{n}$, then $G$ is said continuous on $X^{n}$.

Definition 2.10 is equivalent to [15, Definition 2.16] for $k=1$.

Definition 2.11. Let $\left(X^{n}, M^{n}, *, \preceq_{l}\right)$ be k-poFMS for $l=\frac{n}{k} \in \mathbb{N}$. The mappings $T, G: X^{k} \rightarrow X^{k}$ are said to be J-compatible if for $t>0$,

$$
\lim _{n \rightarrow \infty} M^{k}\left(G T\left(X_{n}\right), T G\left(X_{n}\right), t\right)=1,
$$

for $\left\{X_{n}\right\} \subset X^{k}$, such that $\lim _{n \rightarrow \infty} T\left(X_{n}\right)=\lim _{n \rightarrow \infty} G\left(X_{n}\right)=X$ for $X \in X^{k}$.

Remark 2.12. Definition 2.11 is equivalent to [20, Definition 2.18] for $n=1$.

Definition 2.13. Let $\left(X^{n}, M^{n}, *, \preceq_{l}\right)$ be a k-poFMS for $k=\frac{n}{k} \in \mathbb{N}$. Let $\Phi=\left(\sigma_{1}, \sigma_{2}, \cdots, \sigma_{l}\right)$ be an ltuple of mappings from $\Lambda_{n}$ into itself. Two mappings $F: X^{n} \rightarrow X^{k}$ and $g: X^{k} \rightarrow X^{k}$ are said to be $\Phi_{l}$-compatible, if $\left\{g\left(x_{m}^{1}, \cdots, x_{m}^{k}\right)\right\}_{m \geqslant 0}, \cdots,\left\{g\left(x_{m}^{i k+1}, \cdots, x_{m}^{i k+k}\right)\right\}_{m} \geqslant 0, \cdots,\left\{g\left(x_{m}^{n-k+1}, \cdots, x_{m}^{n}\right)\right\}_{m} \geqslant 0$ are monotone for sequences $\left\{x_{m}^{1}\right\}_{m} \geqslant 0,\left\{x_{m}^{2}\right\}_{m} \geqslant 0, \cdots,\left\{x_{m}^{n}\right\}_{m} \geqslant 0 \subset X$ and

$$
\exists \lim _{m \rightarrow \infty} F\left(x_{m}^{\sigma_{i+1}(1)}, \cdots, x_{m}^{\sigma_{i+1}(n)}\right)=\lim _{m \rightarrow \infty} g\left(x_{m}^{i k+1}, \cdots, x_{m}^{i k+k}\right) \in X^{k}, \quad \text { for } i \in\{0, \cdots, l-1\},
$$

we have

$$
\lim _{m \rightarrow \infty} M^{k}\left(g F\left(x_{m}^{\sigma_{i+1}(1)}, \cdots, x_{m}^{\sigma_{i+1}(n)}\right), F\left(g\left(x_{m}^{\sigma_{i+1}(1)}, \cdots, x_{m}^{\sigma_{i+1}(k)}\right), \cdots, g\left(x_{m}^{\sigma_{i+1}(n-k+1)}, \cdots, x_{m}^{\sigma_{i+1}(n)}\right)\right), t\right)=1,
$$

for all $t>0$.

It is easy to know that Definition 2.13 is equivalent to [20, Definition 2.18] for $k=1$.

Definition 2.14. We will say that the maps $f, g$ are weakly compatible, if $f g\left(x_{1}, \cdots, x_{k}\right)=g f\left(x_{1}, \cdots, x_{k}\right)$ for $\left(x_{1}, \cdots, x_{k}\right) \in X^{k}$ such that $f\left(x_{1}, \cdots, x_{k}\right)=g\left(x_{1}, \cdots, x_{k}\right)$ for $f, g: X^{k} \rightarrow X^{k}$.

Definition 2.14 is equivalent to a Definition in [4].

Lemma 2.15 ([11]). Let $\varphi \in \Phi_{k}$ be given. Then for each $t_{1}>0$ and $\mathbb{T}=\left\{\left\{t_{m}\right\} \mid t_{m+1}=\varphi^{N\left(t_{0}^{(m)}\right)}\left(t_{0}^{(m)}\right), t_{0}^{(m)} \in\right.$ $\left.\mathrm{L}_{\mathfrak{t}_{\mathrm{m}}}, \mathrm{m} \in \mathbb{N}^{+}\right\}$, we have $\inf _{\left\{\mathrm{t}_{\mathrm{m}}\right\} \in \mathbb{T}}\left\{\mathrm{t}_{0} \mid \lim _{\mathrm{m} \rightarrow \infty} \mathrm{t}_{\mathfrak{m}}=\mathrm{t}_{0}\right\}=0$.

Lemma 2.16 ([11]). Let $\varphi \in \Phi_{\mathrm{k}}$ be a function. For any $\mathrm{t}>0$ and each $\mathrm{r} \in \mathrm{L}_{\mathrm{t}}$, there exists $\mathrm{N}^{\prime}(\mathrm{r}) \in \mathbb{N}^{+}$such that $\varphi^{N^{\prime}(r)}(r)<t \leqslant \varphi^{N^{\prime}(r)-1}(r)$ and $\varphi^{n}(r)<t$ for $n \geqslant N^{\prime}(r)$. 


\section{Main results}

In this section, we give the main results of this paper.

Lemma 3.1. If $\left(\mathrm{X}^{\mathrm{n}}, \mathrm{M}^{\mathrm{n}}, *, \preceq_{\mathrm{l}}\right)$ is a k-poFMS under some $\mathrm{t}$-norm and $\mathrm{x}, \mathrm{y} \in \mathrm{X}^{\mathrm{n}}$, then $\mathrm{M}^{\mathrm{n}}(\mathrm{x}, \mathrm{y}, \cdot)$ is a nondecreasing function on $(0, \infty)$.

Proof. Since $1 * a \geqslant a$, by (POF -4$)$, we obtain

$$
\begin{aligned}
M^{\mathrm{n}}(x, y, t+s) & \geqslant M^{\mathrm{n}}(x, y, t) * M^{\mathrm{n}}(y, y, s) \\
& \geqslant M^{\mathrm{n}}(x, y, t) * 1=M^{\mathrm{n}}(x, y, t),
\end{aligned}
$$

for $t, s>0$, which implies that $M^{n}$ is a non-decreasing function.

Lemma 3.2. If $\left(X^{n}, M^{n}, *, \preceq_{l}\right)$ is a k-poFMS with $M^{n}(x, y, \cdot): \mathbb{R}^{+} \rightarrow \mathbb{I}$ is continuous, then $M^{n}$ is a continuous mapping on $\mathrm{X}^{\mathrm{n}} \times \mathrm{X}^{\mathrm{n}} \times(0, \infty)$.

Proof. Let $x, y \in X^{n}$ and $t>0$ be given. Let $\left\{\left(x_{m}^{\prime}, y_{m}^{\prime}, t_{m}^{\prime}\right)\right\}$ be a sequence in $X^{n} \times X^{n} \times(0, \infty)$ such that converges to $(x, y, t)$. Since $\left\{M^{n}\left(x_{m}^{\prime}, y_{m}^{\prime}, t_{m}^{\prime}\right)\right\}$ is a sequence in $(0,1]$, there exists a subsequence $\left\{\left(x_{m}, y_{m}, t_{m}\right)\right\}$ of $\left\{\left(x_{m}^{\prime}, y_{m}^{\prime}, t_{m}^{\prime}\right)\right\}$ converges to some point of $[0,1]$.

For $\sigma>0$ such that $\sigma<\frac{t}{2}$, there is $n_{0} \in \mathbb{N}$ such that $\left|t-t_{m}\right|<\sigma$ for $m \geqslant n_{0}$. Hence,

$$
M^{n}\left(x_{m}, y_{m}, t_{m}\right) \geqslant M^{n}\left(x_{m}, x, \frac{\sigma}{2}\right) * M^{n}(x, y, t-2 \sigma) * M^{n}\left(y, y_{m}, \frac{\sigma}{2}\right),
$$

and

$$
M^{n}(x, y, t+2 \sigma) \geqslant M^{n}\left(x_{m}, x, \frac{\sigma}{2}\right) * M^{n}\left(x_{m}, y_{m}, t_{m}\right) * M^{n}\left(y_{m}, y, \frac{\sigma}{2}\right),
$$

for $\mathrm{m} \geqslant \mathrm{n}_{0}$. By taking limit when $\mathrm{m} \rightarrow \infty$, we obtain

$$
\lim _{m \rightarrow \infty} M^{n}\left(x_{m}, y_{m}, t_{m}\right) \geqslant 1 * M^{n}(x, y, t-2 \sigma) * 1=M^{n}(x, y, t-2 \sigma),
$$

and

$$
M^{n}(x, y, t+2 \sigma) \geqslant 1 * \lim _{m \rightarrow \infty} M^{n}\left(x_{m}, y_{m}, t_{m}\right) * 1=\lim _{m \rightarrow \infty} M^{n}\left(x_{m}, y_{m}, t_{m}\right) .
$$

Since $M^{n}(x, y, t)$ is continuous on $t \in(0, \infty)$, we immediately deduce that $M^{n}(x, y, t)=\lim _{n \rightarrow \infty} M^{n}\left(x_{m}\right.$, $\left.y_{m}, t_{m}\right)$. Therefore $M^{n}$ is continuous on $X^{n} \times X^{n} \times(0, \infty)$.

Lemma 3.3. Let $\left(\mathrm{X}^{\mathrm{n}}, \mathrm{M}^{\mathrm{n}}, *, \preceq_{\mathrm{l}}\right)$ be a k-poFMS such that $*$ is a continuous t-norm. Let $\mathrm{M}^{\mathrm{n}}: \mathrm{X}^{\mathrm{n}} \times \mathrm{X}^{\mathrm{n}} \times \mathbb{R}^{+} \rightarrow \mathbb{I}$ be defined by

$$
M^{n}(A, B, t)=*_{i=1}^{n} M\left(a_{i}, b_{i}, t\right),
$$

for $A=\left(a_{1}, a_{2}, \cdots, a_{n}\right), B=\left(b_{1}, b_{2}, \cdots, b_{n}\right) \in X^{n}$, and $t>0$. Then the following properties hold:

(i) $\left(\mathrm{X}^{\mathrm{n}}, \mathrm{M}^{\mathrm{n}}, *, \preceq_{\mathrm{l}}\right)$ is also FMS.

(ii) Let $\left\{A_{m}=\left(a_{m}^{1}, a_{m}^{2}, \cdots, a_{m}^{n}\right)\right\}$ be a sequence on $X^{n}$ and $A=\left(a_{1}, a_{2}, \cdots, a_{n}\right) \in X^{n}$ be given. Then $\left\{A_{m}\right\} \rightarrow A$, if and only if $\left\{a_{m}^{i}\right\} \rightarrow a_{i}$ for $i \in\{1,2, \cdots, n\}$.

(iii) If $(\mathrm{X}, \mathrm{M}, *)$ is complete, then $\left(\mathrm{X}^{\mathrm{n}}, \mathrm{M}^{\mathrm{n}}, *\right)$ is complete.

Proof. The proof of Lemma 3.3 is similar to [16, Lemma 13], by Definition 2.7.

Lemma 3.4. If $X \preceq_{l} Y$ for $\frac{n}{l} \in \mathbb{N}$, we have $\left(x_{\sigma(1)}, \cdots, x_{\sigma(n)}\right) \preceq_{l}\left(y_{\sigma(1)}, \cdots, y_{\sigma(n)}\right)$ for $\sigma \in \Omega_{A B}$, $\left(x_{\sigma(1)}, \cdots, x_{\sigma(n)}\right) \succeq_{l}\left(y_{\sigma(1)}, \cdots, y_{\sigma(n)}\right)$ for $\sigma \in \Omega_{A B}^{\prime}$.

Proof. Let $k=\frac{n}{l}$ and $i \in\{0,1, \cdots, l-1\}$ be given. Fix $\sigma \in \Omega_{A B}$. Then, for $i+1 \in A$, we have $\sigma(i+1) \in A$, and $x_{\sigma(i k+j)} \preceq_{\sigma(i+1)} y_{\sigma(i k+j)}$ implies that $x_{\sigma(i k+j)} \preceq y_{\sigma(i k+j)}$, which means that $x_{\sigma(i k+j)} \preceq_{i+1} y_{\sigma(i k+j)}$ 
for $j=1,2, \cdots, k$.

For $i+1 \in B$, we have $\sigma(i+1) \in B$, and $x_{\sigma(i k+j)} \preceq_{\sigma(i+1)} y_{\sigma(i k+j)}$ implies that $x_{\sigma(i k+j)} \succeq y_{\sigma(i k+j)}$, which means that $x_{\sigma(i k+j)} \preceq_{i+1} y_{\sigma(i k+j)}$ for $j=1,2, \cdots, k$.

In any case, if $\sigma \in \Omega_{A B}$, then $x_{\sigma(i k+j)} \preceq_{i+1} y_{\sigma(i k+j)}$ for $i \in\{0,1, \cdots, l-1\}$. It follows that

$$
\left(x_{\sigma(1)}, \cdots, x_{\sigma(n)}\right) \preceq\left(y_{\sigma(1)}, \cdots, y_{\sigma(n)}\right) .
$$

Now, fix $\sigma \in \Omega_{A B}^{\prime}$. For $i+1 \in A$, then $\sigma(i+1) \in B$, and $x_{\sigma(i k+j)} \preceq_{\sigma(i+1)} y_{\sigma(i k+j)}$ implies that $x_{\sigma(i k+j)} \succeq y_{\sigma(i k+j)}$, which means that $x_{\sigma(i k+j)} \succeq_{i+1} y_{\sigma(i k+j)}$. For $i \in B$, we have $\sigma(i+1) \in A$. And $x_{\sigma(i k+j)} \preceq_{\sigma(i+1)} y_{\sigma(i k+j)}$ implies $x_{\sigma(i k+j)} \preceq y_{\sigma(i k+j)}$, which means that $x_{\sigma(i k+j)} \succeq_{i+1} y_{\sigma(i k+j)}$.

In any case, if $\sigma \in \Omega_{A B}^{\prime}$, then $x_{\sigma(i k+j)} \preceq_{i+1} y_{\sigma(i k+j)}$ for $i \in\{0,1, \cdots, l-1\}$. It follows that

$$
\left(x_{\sigma(1)}, \cdots, x_{\sigma(n)}\right) \preceq_{l}\left(y_{\sigma(1)}, \cdots, y_{\sigma(n)}\right) .
$$

Lemma 3.5. Let $\left(\mathrm{X}^{\mathrm{n}}, \mathrm{M}^{\mathrm{n}}, *, \preceq_{\mathrm{l}}\right)$ be a k-poFMS such that $*$ is a $\mathrm{t}$-norm of $\mathrm{H}$-type. Let $\left\{\mathrm{X}_{\mathrm{m}}\right\} \subseteq \mathrm{X}^{\mathrm{n}}$ be a sequence in $\left(X^{n}, M^{n}, *, \preceq_{l}\right)$. If there exists a function $\varphi \in \Phi_{k}$ satisfying

(i) $\varphi(t)>0$ for $t>0$;

(ii) $M^{\mathrm{n}}\left(X_{i}, X_{j}, \varphi(t)\right) \geqslant M^{n}\left(X_{i-1}, X_{j-1}, t\right)$ for $i, j \in \mathbb{N}$ and $t>0$;

(iii) $\lim _{\mathrm{t} \rightarrow \infty} \mathrm{M}^{\mathrm{n}}\left(\mathrm{X}_{0}, \mathrm{X}_{1}, \mathrm{t}\right)=1$,

then $\left\{\mathrm{X}_{\mathrm{m}}\right\}$ is a Cauchy sequence.

Proof. By Lemma 3.3, it is easy to know that $\left(X^{n}, M^{n}, *\right.$, ) is a FMS. Next, we proceed with the following steps:

Step 1 . We claim that for any $t>0$,

$$
M^{n}\left(X_{m}, X_{m+1}, t\right) \rightarrow 1 \text { as } m \rightarrow \infty
$$

By (iii), for any $\varepsilon \in(0,1)$, there exists $t_{1}>0$ such that $M^{n}\left(X_{0}, X_{1}, t_{1}\right)>1-\varepsilon$. For $t_{1}>0$, since $\varphi \in \Phi_{k}$ and Lemma 2.15, we have $\inf _{\left\{t_{\mathfrak{m}}\right\} \in \mathbb{T}}\left\{t_{0} \mid \lim _{\mathfrak{m} \rightarrow \infty} t_{\mathfrak{m}}=t_{0}\right\}=0$ for

$$
\mathbb{T}=\left\{\left\{\mathfrak{t}_{\mathrm{m}}\right\} \mid \mathrm{t}_{\mathrm{m}+1}=\varphi^{\mathrm{N}\left(\mathrm{t}_{0}^{(\mathrm{m})}\right)}\left(\mathrm{t}_{0}^{(\mathrm{m})}\right), \mathrm{t}_{0}^{(\mathrm{m})} \in \mathrm{L}_{\mathrm{t}_{\mathrm{m}}}, \mathrm{m} \in \mathbb{N}^{+}\right\} .
$$

For each $t>0$, there exists $\left\{x_{m}\right\} \in \mathbb{T}$ such that $\lim _{m \rightarrow \infty} x_{m}<t$. So, there exists $n_{0} \in \mathbb{N}$ such that $t \geqslant x_{m}$ for each $m \geqslant n_{0}$. Since $M^{n}(X, Y, \cdot)$ is non-decreasing and satisfies (ii), we obtain

$$
\begin{aligned}
1-\varepsilon & <M^{n}\left(X_{0}, X_{1}, t_{1}\right) \leqslant M^{n}\left(X_{1}, X_{2}, \varphi\left(t_{0}^{(1)}\right)\right) \leqslant \cdots \leqslant M^{n}\left(X_{n_{1}}, X_{n_{1}+1}, \varphi^{n_{1}}\left(t_{0}^{(1)}\right)\right) \\
& \leqslant M^{n}\left(X_{n_{1}}, X_{n_{1}+1}, t_{0}^{(2)}\right) \leqslant \cdots \leqslant M^{n}\left(X_{n_{1}+n_{2}}, X_{n_{1}+n_{2}+1}, \varphi^{n_{2}}\left(t_{0}^{(2)}\right)\right) \\
& \vdots \\
& \leqslant M^{n}\left(X_{n_{1} \cdots+n_{n_{0}}+i}, X_{n_{1}+\cdots+n_{n_{0}}+i+1}, \varphi^{n_{n_{0}}+i}\left(t_{0}^{\left(n_{0}\right)}\right)\right) \leqslant M^{n}\left(X_{m}, X_{m+1}, t\right),
\end{aligned}
$$

for $m=n_{1}+\cdots+n_{n_{0}}+i, i \in \mathbb{N}$, and $n_{j} \geqslant N\left(t_{0}^{(j)}\right), j \in\left\{1, \cdots, n_{n_{0}}\right\}$, which implies that (3.1) holds.

Step 2. We claim that for any $t>0$,

$$
M^{n}\left(X_{i}, X_{j}, t\right) \geqslant *^{j-i} M^{n}\left(X_{i}, X_{i+1}, t-\varphi^{N^{\prime}(r)}(r)\right), \text { for } j \geqslant i+1,
$$

where $r \geqslant t$. Since $\varphi \in \Phi_{k}$, for any $t>0$, there exist $r>t$ and $N^{\prime}(r) \in \mathbb{N}$ such that $\varphi^{N^{\prime}(r)}(r)<t$, by 
Lemma 3.1. By $(\mathrm{POF}-4)$, (ii) and the monotonicity of $*$, we get

$$
\begin{aligned}
M^{n}\left(X_{i}, X_{j+1}, t\right) & =M^{n}\left(X_{i}, X_{j+1}, t-\varphi^{N^{\prime}(r)}(r)+\varphi^{N^{\prime}(r)}(r)\right) \\
& \geqslant M^{n}\left(X_{i}, X_{i+1}, t-\varphi^{N^{\prime}(r)}(r)\right) * M^{n}\left(X_{i+1}, X_{j+1}, \varphi^{N^{\prime}(r)}(r)\right) \\
& \geqslant M^{n}\left(X_{i}, X_{i+1}, t-\varphi^{N^{\prime}(r)}(r)\right) * M^{n}\left(X_{i}, X_{j}, \varphi^{N^{\prime}(r)-1}(r)\right) \\
& \geqslant M^{n}\left(X_{i}, X_{i+1}, t-\varphi^{N^{\prime}(r)}(r)\right) * M^{n}\left(X_{i}, X_{j}, t\right) \\
& \geqslant M^{n}\left(X_{i}, X_{i+1}, t-\varphi^{N^{\prime}(r)}(r)\right) *\left(*^{j-i} M^{n}\left(X_{i}, X_{i+1}, t-\varphi^{N^{\prime}(r)}(r)\right)\right. \\
& =*^{j+1-i} M^{k}\left(X_{i}, X_{i+1}, t-\varphi^{N^{\prime}(r)}(r)\right) .
\end{aligned}
$$

Thus, we prove that if (3.2) holds for $j \geqslant i+1$, then it also holds for $j+1$.

Step 3. We claim that $\left\{X_{m}\right\}$ is a Cauchy sequence. As $*$ is equi-continuous at $a=1$, for $\varepsilon \in(0,1)$ there exists $\eta \in(0,1)$ such that

$$
\text { if } a \in(1-\eta, 1] \text {, then } *^{n} a>1-\varepsilon, \quad \text { for } n \in \mathbb{N} \text {. }
$$

It follows from (3.1) that there exists $n_{1} \in \mathbb{N}$ such that $M^{n}\left(X_{m}, X_{m+1}, t-\phi(r)\right)>1-\eta$ for $m \geqslant n_{1}$. So, by (3.3), we have

$$
*^{j-i} M^{n}\left(X_{i}, X_{i+1}, t-\phi(r)\right)>1-\varepsilon,
$$

for $j \geqslant i+1$. By (3.2) and (3.4), we get for each $t>0$ and $\varepsilon \in(0,1), M^{n}\left(X_{i}, X_{j}, t\right)>1-\varepsilon$ for $j \geqslant i+1 \geqslant n_{1}$, which implies that $\left\{X_{m}\right\}$ is a Cauchy sequence.

Theorem 3.6. Let $\left(\mathrm{X}^{\mathrm{k}}, \mathrm{M}^{\mathrm{k}}, *, \preceq_{1}\right)$ be a complete $\mathrm{k}$-poFMS such that $*$ is a continuous $\mathrm{t}$-norm of $\mathrm{H}$-type. Let $\mathrm{T}: \mathrm{X}^{\mathrm{k}} \rightarrow \mathrm{X}^{\mathrm{k}}$ and $\mathrm{G}: \mathrm{X}^{\mathrm{k}} \rightarrow \mathrm{X}^{\mathrm{k}}$ be two mappings such that $\mathrm{T}$ is $a \mathrm{G}_{\mathrm{k}}$-isotone mapping and $\mathrm{T}\left(\mathrm{X}^{\mathrm{k}}\right) \subseteq \mathrm{G}\left(\mathrm{X}^{\mathrm{k}}\right)$. Assume that there exists $\varphi \in \Phi_{k}$ such that, for $\mathrm{t}>0$ and $\left(\mathrm{y}_{1}, \cdots, \mathrm{y}_{\mathrm{k}}\right),\left(v_{1}, \cdots, v_{\mathrm{k}}\right) \in \mathrm{X}^{\mathrm{k}}$ with $\mathrm{G}\left(\mathrm{y}_{1}, \cdots, \mathrm{y}_{\mathrm{k}}\right) \preceq_{1}$ $\mathrm{G}\left(v_{1}, \cdots, v_{\mathrm{k}}\right)$,

$$
M^{k}\left(T\left(y_{1}, \cdots, y_{k}\right), T\left(v_{1}, \cdots, v_{k}\right), \varphi(t)\right) \geqslant M^{k}\left(G\left(y_{1}, \cdots, y_{k}\right), G\left(v_{1}, \cdots, v_{k}\right), t\right) .
$$

Also suppose that either

(C1) T and $\mathrm{G}$ are continuous and $\mathrm{J}$-compatible and $\mathrm{M}^{\mathrm{k}}(\mathrm{X}, \mathrm{Y}, \cdot): \mathbb{R}^{+} \rightarrow \mathbb{I}$ is continuous; or

(C2) $\left(X^{k}, \tau_{M^{k}}, \preceq\right)$ has the sequential monotone property and $\mathrm{G}\left(\mathrm{X}^{\mathrm{k}}\right)$ is closed.

If there exists $\left(y_{0}^{1}, \cdots, y_{0}^{k}\right) \in X^{k}$ such that $\mathrm{G}\left(y_{0}^{1}, y_{0}^{2}, \cdots, y_{0}^{k}\right) \asymp_{1} \mathrm{~T}\left(y_{0}^{1}, y_{0}^{2}, \cdots, y_{0}^{k}\right)$ and

$$
\lim _{t \rightarrow \infty} M^{k}\left(G\left(y_{0}^{1}, y_{0}^{2}, \cdots, y_{0}^{k}\right), T\left(y_{0}^{1}, y_{0}^{2}, \cdots, y_{0}^{k}\right), t\right)=1,
$$

then $\mathrm{T}$ and $\mathrm{G}$ have a coincidence point.

Proof. Since $\left(X^{k}, M^{k}, *, \preceq_{1}\right)$ is a complete $\mathrm{k}$-poFMS such that $*$ is a continuous t-norm of H-type. Let $Y_{0}=\left(y_{0}^{1}, y_{0}^{2}, \cdots, y_{0}^{k}\right) \in X^{k}$ such that $G\left(Y_{0}\right) \asymp_{1} T\left(Y_{0}\right)$ and $\lim _{t \rightarrow \infty} M^{k}\left(G\left(Y_{0}\right), T\left(Y_{0}\right), t\right)=1$. Since $T\left(X^{k}\right) \subseteq$ $G\left(X^{k}\right)$, there exists $Y_{1}=\left(y_{1}^{1}, \cdots, y_{1}^{k}\right) \in X^{k}$ such that $G\left(Y_{1}\right)=T\left(Y_{0}\right)$. Recursively, we see that, for every $\mathrm{m} \in \mathbb{N}$, there exists $Y_{\mathrm{m}+1}=\left(y_{\mathrm{m}+1}^{1}, \cdots, y_{\mathrm{m}+1}^{\mathrm{k}}\right) \in X^{\mathrm{k}}$ such that $\mathrm{G}\left(Y_{\mathrm{m}+1}\right)=T\left(Y_{\mathrm{m}}\right)$. Set $Z_{0}=G\left(Y_{0}\right)$ and $Z_{m+1}=G\left(Y_{m+1}\right)=T\left(Y_{m}\right)$ for every $m \in \mathbb{N}$.

Since $G\left(Y_{0}\right) \asymp_{1} T\left(Y_{0}\right)$, we suppose that $G\left(Y_{0}\right) \preceq_{1} T\left(Y_{0}\right)$, i.e., $Z_{0} \preceq_{1} Z_{1}$. Assume that $Z_{m-1} \preceq_{1} Z_{m}$ for some $m \in \mathbb{N}_{0}$, that is, $G\left(Y_{m-1}\right) \preceq_{1} G\left(Y_{m}\right)$. Since $T$ is a $G_{k}$-isotone mapping, we get $Z_{m}=T\left(Y_{m-1}\right) \preceq_{1}$ $T\left(Y_{m}\right)=Z_{m+1}$. This actually means that the sequence $\left\{Z_{m}\right\}$ is non-decreasing. Using (3.5) and monotonicity of $\left\{Z_{m}\right\}$, we get

$$
M^{k}\left(Z_{n}, Z_{m}, \varphi(t)\right)=M^{k}\left(T\left(Y_{n-1}\right), T\left(Y_{m-1}\right), \varphi(t)\right)
$$




$$
\begin{aligned}
& \geqslant M^{k}\left(G\left(Y_{n-1}\right), G\left(Y_{m-1}\right), t\right) \\
& =M^{k}\left(Z_{n-1}, Z_{m-1}, t\right),
\end{aligned}
$$

for $m, n \in \mathbb{N}$ and $t>0$. Obviously, the inequality (3.5) implies that $\varphi(t)>0$ for $t>0$. Indeed, if there exists some $t_{0}>0$ such that $\varphi\left(t_{0}\right)=0$, then it follows from (3.5) that

$$
0=M^{k}\left(T(Y), T(Y), \varphi\left(t_{0}\right)\right) \geqslant M^{k}\left(G(Y), G(Y), t_{0}\right)=1
$$

which is a contradiction. Since $\lim _{t \rightarrow \infty} M^{k}\left(G\left(Y_{0}\right), T\left(Y_{0}\right), t\right)=1$, we have $\lim _{t \rightarrow \infty} M^{k}\left(Z_{0}, Z_{1}, t\right)=1$. By Lemma $3.5,\left\{Z_{m}\right\}$ is a Cauchy sequence.

Now suppose that the condition (C1) holds. Since $\left(X^{k}, M^{k}, *, \preceq_{1}\right)$ is complete, there exists $\hat{Z} \in X^{k}$ such that $\lim _{m \rightarrow \infty} Z_{m}=\hat{Z}$, that is,

$$
\lim _{m \rightarrow \infty} T\left(Y_{m}\right)=\lim _{m \rightarrow \infty} G\left(Y_{m}\right)=\hat{Z} .
$$

Since $\mathrm{T}$ and $\mathrm{G}$ are J-compatible, we have

$$
\lim _{m \rightarrow \infty} M^{k}\left(G\left(G\left(Y_{m+1}\right)\right), T\left(G\left(Y_{m}\right)\right), t\right)=\lim _{m \rightarrow \infty} M^{k}\left(G\left(T\left(Y_{m}\right)\right), T\left(G\left(Y_{m}\right)\right), t\right)=1,
$$

for $t>0$. As $G$ is continuous, we have

$$
\lim _{m \rightarrow \infty} G\left(G\left(Y_{m}\right)\right)=G(\hat{Z}) .
$$

Using Lemma 3.2, we find that $M^{k}$ is a continuous mapping on $X^{k} \times X^{k} \times(0, \infty)$. By the continuity of $M^{k}$ and (3.6), (3.7), (3.8), we have $1=\lim _{m \rightarrow \infty} M^{k}\left(G\left(G\left(Y_{m+1}\right)\right), T\left(G\left(Y_{m}\right)\right), t\right)=M^{k}(G(\hat{Z}), T(\hat{Z}), t)$ for $t>0$, which implies $G(\hat{Z})=T(\hat{Z})$, i.e., $\hat{Z}$ is a coincidence point of $T$ and $G$.

Now, suppose that the condition (C2) holds. Since $\left(X^{k}, M^{k}, *, \preceq_{1}\right)$ is complete and $G\left(X^{k}\right)$ is closed, there exists $Z \in X^{k}$ such that $\lim _{m \rightarrow \infty} T\left(Y_{m}\right)=\lim _{m \rightarrow \infty} G\left(Y_{m}\right)=G(Z)$. Since $\left(X^{k}, \tau_{M^{k}}, \preceq\right)$ has the sequential monotone property, we have $G\left(Y_{m}\right) \preceq_{1} G(Z)$ for $m \in \mathbb{N}_{0}$. Since $\varphi \in \Phi_{k}$, for each $t>0$ there exist $r>t$ and $N(r) \in \mathbb{N}$ such that $\varphi^{n}(r)<t$, for $n \geqslant N(r)$, by Lemma 2.16. So, by (3.5) and the monotonicity of $M^{k}(X, Y, \cdot)$, we have

$$
\begin{aligned}
M^{k}\left(T\left(Y_{m}\right), T(Z), t\right) & \geqslant M^{k}\left(T\left(Y_{m}\right), T(Z), \varphi^{N(r)}(r)\right) \\
& \geqslant M^{k}\left(G\left(Y_{m}\right), G(Z), \varphi^{N(r)-1}(r)\right) \\
& \geqslant M^{k}\left(G\left(Y_{m}\right), G(Z), t\right),
\end{aligned}
$$

for $t>0$ and $m \in \mathbb{N}_{0}$. Letting $m \rightarrow \infty$ in the above inequality, we get $T\left(Y_{m}\right) \rightarrow T(Z)$. By the uniqueness of the limit, we conclude that $G(Z)=T(Z)$, i.e., $Z$ is a coincidence point of $T$ and $G$.

Theorem 3.7. In addition to the hypotheses of Theorem 3.6, let $\mathrm{G}$ be weakly compatible with $\mathrm{T}$ if assumption (C2) holds. Suppose that for all coincidence points $\mathrm{Y}, \mathrm{V} \in \mathrm{X}^{\mathrm{k}}$ of mappings $\mathrm{T}$ and $\mathrm{G}$, there exists $\mathrm{U} \in \mathrm{X}^{\mathrm{k}}$ such that

(C3) $\mathrm{G}(\mathrm{U})$ is comparable to $\mathrm{G}(\mathrm{Y})$ and $\mathrm{G}(\mathrm{V})$;

(C4) $\lim _{\mathrm{t} \rightarrow \infty} M^{k}(\mathrm{G}(\mathrm{U}), \mathrm{G}(\mathrm{Y}), \mathrm{t})=\lim _{\mathrm{t} \rightarrow \infty} \mathrm{M}^{\mathrm{k}}(\mathrm{G}(\mathrm{U}), \mathrm{G}(\mathrm{V}), \mathrm{t})=1$.

Then $\mathrm{T}$ and $\mathrm{G}$ have a unique common fixed point.

Proof. Let $\mathrm{U}_{0}=\mathrm{U}$ and define a sequence $\left\{\mathrm{G}\left(\mathrm{U}_{\mathrm{m}}\right)\right\}$ by $\mathrm{G}\left(\mathrm{U}_{\mathrm{m}+1}\right)=\mathrm{T}\left(\mathrm{U}_{\mathrm{m}}\right)$ for $\mathrm{m} \in \mathbb{N}$. We assume that $\mathrm{G}(\mathrm{Y}) \preceq_{1} \mathrm{G}\left(\mathrm{U}_{0}\right)$. Since $T$ is a $\mathrm{G}_{\mathrm{k}}$-isotone mapping, we have $\mathrm{G}(\mathrm{Y})=\mathrm{T}(\mathrm{Y}) \preceq_{1} \mathrm{~T}\left(\mathrm{U}_{0}\right)=\mathrm{G}\left(\mathrm{U}_{1}\right)$. By induction we obtain $G(Y) \preceq_{1} G\left(U_{m}\right)$ for $m \in \mathbb{N}$. Owing to $\lim _{t \rightarrow \infty} M^{k}\left(G\left(U_{0}\right), G(Y), t\right)=1$, for any $\varepsilon \in(0,1)$, there exists $t_{1}>0$ such that $M^{k}\left(G\left(U_{0}\right), G(Y), t_{1}\right)>1-\varepsilon$. For each $t_{1}>0$, by Lemma 2.15, we obtain $\inf _{\left\{t_{\mathfrak{m}}\right\} \in T}\left\{t_{0} \mid \lim _{\mathfrak{m} \rightarrow \infty} t_{\mathfrak{m}}=t_{0}\right\}=0$ for $\mathbb{T}=\left\{\left\{t_{m}\right\} \mid t_{m+1}=\varphi^{N\left(t_{0}^{(m)}\right)}\left(t_{0}^{(m)}\right), t_{0}^{(m)} \in L_{t_{m}}, m \in \mathbb{N}^{+}\right\}$. For each 
$t>0$, there exist $\left\{t_{m}\right\} \in \mathbb{T}$ and $N\left(t_{0}^{\left(m_{0}\right)}\right) \in \mathbb{N}$ such that $\varphi^{n}\left(t_{0}^{\left(m_{0}\right)}\right)<t$ for $n \geqslant N\left(t_{0}^{\left(m_{0}\right)}\right)$. So, by (3.5) and the monotonicity of $M^{k}(X, Y, \cdot)$, we get

$$
\begin{aligned}
1-\varepsilon & <M^{k}\left(G\left(U_{0}\right), G(Y), t_{1}\right) \leqslant M^{k}\left(G\left(U_{0}\right), G(Y), t_{0}^{(1)}\right) \leqslant M^{k}\left(T\left(U_{0}\right), T(Y), \varphi\left(t_{0}^{(1)}\right)\right) \\
& \leqslant M^{k}\left(G\left(U_{1}\right), G(Y), \varphi\left(t_{0}^{(1)}\right)\right) \leqslant \cdots \leqslant M^{k}\left(G\left(U_{N\left(t_{0}^{(1)}\right)}, G(Y), \varphi^{N\left(t_{0}^{(1)}\right)}\left(t_{0}^{(1)}\right)\right)\right. \\
& \leqslant M^{k}\left(G\left(U_{N\left(t_{0}^{(1)}\right)}, G(Y), t_{0}^{(2)}\right) \leqslant \cdots \leqslant M^{k}\left(G\left(U_{m}\right), G(Y), \varphi^{N\left(t_{0}^{\left(m_{0}\right)}\right)+i}\left(t_{0}^{\left(m_{0}\right)}\right)\right)\right. \\
& \leqslant M^{k}\left(G\left(U_{m}\right), G(Y), t\right),
\end{aligned}
$$

for $m=N\left(t_{0}^{(1)}\right)+\cdots+N\left(t_{0}^{m_{0}}\right)+i$ and $i \in \mathbb{N}$. Since $\varepsilon, t>0$ are arbitrary, we deduce that

$$
\mathrm{M}^{\mathrm{k}}\left(\mathrm{G}\left(\mathrm{U}_{\mathrm{m}}\right), \mathrm{G}(\mathrm{Y}), \mathrm{t}\right) \rightarrow 1 \text { as } \mathrm{m} \rightarrow \infty \text {. }
$$

This shows that $\lim _{m \rightarrow \infty} G\left(U_{m}\right)=G(Y)$. Similarly, we find that $\lim _{m \rightarrow \infty} G\left(U_{m}\right)=G(V)$. The uniqueness of the limit proves that $\lim _{m \rightarrow \infty} \mathrm{G}\left(\mathrm{U}_{\mathrm{m}}\right)=\mathrm{G}(\mathrm{Y})=\mathrm{G}(\mathrm{V})$.

Denote $W=T(Y)=G(Y)$. Since $T$ and $G$ are weakly compatible mappings, we have $T(W)=T G(Y)=$ $\mathrm{GT}(\mathrm{Y})=\mathrm{G}(\mathrm{W})$. So, $\mathrm{W}$ is also a coincidence point of $T$ and $G$. Therefore, $\mathrm{G}(\mathrm{W})=\mathrm{G}(\mathrm{Y})=\mathrm{W}$ and $\mathrm{W}$ is a common fixed point of $T$ and $G$. In order to prove the uniqueness, assume that $W^{*}$ is another common fixed point of $T$ and $G$. Then we have $W^{*}=G\left(W^{*}\right)=G(W)=W$. This completes the proof.

Definition 3.8. Let $F: X^{n} \rightarrow X^{k}$ and $g: X^{k} \rightarrow X^{k}$ be two mappings, where $l=\frac{n}{k} \in \mathbb{N}$. A point $\left(x_{1}, x_{2}, \cdots, x_{n}\right) \in X^{n}$ is a common fixed point of $F$ and $g$ if

$$
F\left(x_{\sigma_{i+1}(1)}, x_{\sigma_{i+1}(2)}, \cdots, x_{\sigma_{i+1}(n)}\right)=g\left(x_{i k+1}, \cdots, x_{i k+k}\right)=\left(x_{i k+1}, \cdots, x_{i k+k}\right), \text { for } i \in\{0,1, \cdots, l-1\} .
$$

Definition 3.9. Given $n \geqslant 2$, the mappings $F: X^{n} \rightarrow X^{k}$ and $g: X^{k} \rightarrow X^{k}$ are weakly compatible for $l=\frac{n}{k} \in \mathbb{N}$, if

$$
\begin{aligned}
& F\left(x_{\sigma_{i+1}(1)}, \cdots, x_{\sigma_{i+1}(n)}\right)=g\left(x_{i k+1}, \cdots, x_{i k+k}\right), \text { for } i \in\{0,1, \cdots, l-1\} \Rightarrow \\
& \quad g F\left(x_{\sigma_{i+1}(1)}, \cdots, x_{\sigma_{i+1}(n)}\right)=F\left(g\left(x_{\sigma_{i+1}(1)}, \cdots, x_{\sigma_{i+1}(k)}\right), \cdots, g\left(x_{\sigma_{i+1}(j k+1)} \cdots,\right.\right. \\
& \left.\quad x_{\sigma_{i+1}(j k+k)}\right), \cdots, g\left(x_{\sigma_{i+1}(n-k+1)}, \cdots, x_{\sigma_{i+1}(n)}\right), \text { for } i \in\{0,1, \cdots, l-1\} .
\end{aligned}
$$

Theorem 3.10. Let $\left(\mathrm{X}^{\mathrm{n}}, \mathrm{M}^{\mathrm{n}}, *, \preceq_{\mathrm{l}}\right)$ be a complete k-poFMS with continuous $\mathrm{t}$-norm $*$ of $\mathrm{H}$-type for $\frac{\mathrm{n}}{\mathrm{k}}$ and $n, k \in \mathbb{N}$. Let $\Phi=\left(\sigma_{1}, \sigma_{2}, \cdots, \sigma_{l}\right)$ be an l-tuple of mappings from $\Lambda_{n}$ into itself verifying $\sigma_{i+1} \in \Omega_{A B}$, if $i+1 \in A$ and $\sigma_{i+1} \in \Omega_{A B}^{\prime}$, if $i+1 \in B$. Suppose that $\mathrm{F}: X^{n} \rightarrow X^{k}$ and $\mathrm{g}: X^{k} \rightarrow X^{k}$ are two mappings, satisfying that $\mathrm{F}$ has the mixed $\mathrm{g}_{\mathrm{k}}$-monotone property on $\mathrm{X}^{\mathrm{k}}$ and $\mathrm{F}\left(\mathrm{X}^{\mathrm{n}}\right) \subseteq \mathrm{g}\left(\mathrm{X}^{\mathrm{k}}\right)$. Assume that there exists $\varphi \in \Phi_{\mathrm{k}}$ such that

$$
M^{k}\left(F\left(x_{1}, \cdots, x_{n}\right), F\left(y_{1}, \cdots, y_{n}\right), \varphi(t)\right) \geqslant \gamma\left(*_{i=0}^{l-1} M^{k}\left(g\left(x_{i k+1}, \cdots, x_{i k+k}\right), g\left(y_{i k+1}, \cdots, y_{i k+k}\right), t\right),\right.
$$

for $\mathrm{t}>0$ and $\mathrm{x}_{1}, \cdots, \mathrm{x}_{\mathrm{n}}, \mathrm{y}_{1}, \cdots, \mathrm{y}_{\mathrm{n}} \in \mathrm{X}$ with

$$
g\left(x_{i k+1}, \cdots, x_{i k+k}\right) \preceq_{i+1} g\left(y_{i k+1} \cdots, y_{i k+k}\right) \text { for } i \in\{0,1, \cdots, l-1\},
$$

where $\gamma:[0,1] \rightarrow[0,1]$ is a mapping such that $*^{l} \gamma(a) \geqslant a$ for $a \in[0,1]$. Suppose that

$$
\begin{aligned}
\gamma\left(*_{i=0}^{l-1} M^{k}\left(g\left(x_{\sigma_{j+1}(i k+1)}, \cdots, x_{\sigma_{j+1}(i k+k)}\right), g\left(y_{\sigma_{j+1}(i k+1)}, \cdots, y_{\sigma_{j+1}(i k+k)}\right), t\right)\right) \\
\geqslant \gamma\left(*_{i=0}^{l-1} M^{k}\left(g\left(x_{i k+1}, \cdots, x_{i k+k}\right), g\left(y_{i k+1}, \cdots, y_{i k+k}\right), t\right)\right),
\end{aligned}
$$

for $j \in\{0,1, \cdots, l-1\}$ and $x_{1}, x_{2}, \cdots, x_{n}, y_{1}, y_{2}, \cdots, y_{n} \in X$, with

$$
g\left(x_{i k+1}, \cdots, x_{i k+k}\right) \preceq_{i+1} g\left(y_{i k+1}, \cdots, y_{i k+k}\right), \text { for } i \in\{0,1, \cdots, l-1\} .
$$

Suppose that either 
(C5) $\mathrm{F}$ and $\mathrm{g}$ are continuous and $\Phi_{\mathrm{l}}$-compatible and $\mathrm{M}^{\mathrm{k}}(\mathrm{X}, \mathrm{Y}, \cdot): \mathbb{R}^{+} \rightarrow \mathbb{I}$ is continuous; or

(C6) $\left(X^{k}, \tau_{M^{k}}, \preceq_{l}\right)$ has the sequential monotone property and $\mathrm{g}\left(\mathrm{X}^{\mathrm{k}}\right)$ is closed.

If there exist $x_{0}^{1}, x_{0}^{2}, \cdots, x_{0}^{n} \in X$ such that

$$
g\left(x_{0}^{i k+1}, \cdots, x_{0}^{i k+k}\right) \preceq_{i+1} F\left(x_{0}^{\sigma_{i+1}(1)}, \cdots, x_{0}^{\sigma_{i+1}(n)}\right),
$$

and

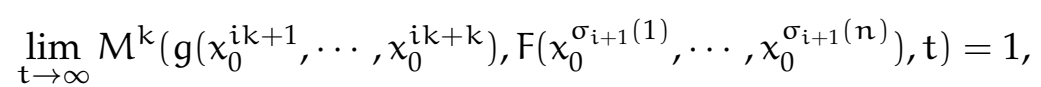

for $i \in\{0,1, \cdots, l-1\}$, then $\mathrm{F}$ and $\mathrm{g}$ have, at least one $\Upsilon_{\mathrm{k}}$-coincidence point.

Furthermore, assume that for all pairs of $\Upsilon_{k}$-coincidence points $\left(x_{1}, x_{2}, \cdots, x_{n}\right),\left(y_{1}, y_{2}, \cdots, y_{n}\right) \in X^{n}$ of $F$ and $g$, there exists $\left(\mathrm{u}_{1}, \mathrm{u}_{2}, \cdots, \mathrm{u}_{\mathrm{n}}\right) \in \mathrm{X}^{\mathrm{n}}$ such that

(C7) $\left(g\left(u_{1}, u_{2}, \cdots, u_{k}\right), \cdots, g\left(u_{n-k+1}, \cdots, u_{n}\right)\right)$ is comparable to $\left(g\left(x_{1}, \cdots, x_{k}\right), \cdots, g\left(x_{n-k+1}, \cdots, x_{n}\right)\right)$ and $\left(g\left(y_{1}, \cdots, y_{k}\right), \cdots, g\left(y_{n-k+1}, \cdots, y_{n}\right)\right)$;

(C8) $\lim _{\rightarrow \infty} M^{k}\left(g\left(u_{i k+1}, \cdots, u_{i k+k}\right), g\left(x_{i k+1}, \cdots, x_{i k+k}\right), t\right)=\lim _{t \rightarrow \infty} M^{k}\left(g\left(u_{i k+1}, \cdots, u_{i k+k}\right), g\left(y_{i k+1}\right.\right.$, $\left.\left.\cdots, y_{i k+k}\right), t\right)=1$ for $i \in\{0,1, \cdots, l-1\}$.

Also, assume that $\mathrm{F}$ is weakly compatible with $\mathrm{g}$ if assumption (C6) holds. Then $\mathrm{F}$ and $\mathrm{g}$ have a unique common fixed point.

Proof. Let $\mathrm{T}: \mathrm{X}^{\mathrm{n}} \rightarrow \mathrm{X}^{\mathrm{n}}$ and $\mathrm{G}: \mathrm{X}^{\mathrm{n}} \rightarrow \mathrm{X}^{\mathrm{n}}$ be two mappings defined by

$$
T(Y)=\left(F\left(y_{\sigma_{1}(1)}, \cdots, y_{\sigma_{1}(n)}\right), \cdots, F\left(y_{\sigma_{l}(1)}, \cdots, y_{\sigma_{l}(n)}\right)\right),
$$

and

$$
G(Y)=\left(g\left(y_{1}, \cdots, y_{k}\right), \cdots, g\left(y_{n-k+1}, \cdots, y_{n}\right)\right),
$$

for $Y \in X^{n}$. It follows from $F\left(X^{n}\right) \subseteq g\left(X^{k}\right)$ that $T\left(X^{n}\right) \subseteq G\left(X^{n}\right)$. By (3.11), definition of $M^{n}$ and the continuity of $*$, there exists $Y_{0}$ such that $G\left(X_{0}\right) \preceq_{l} T\left(x_{0}\right)$ and $\lim _{t \rightarrow \infty} M^{n}\left(G\left(x_{0}\right), T\left(x_{0}\right), t\right)=1$. Suppose that $\left\{Y_{m}\right\}_{m} \geqslant 0 \subset X^{n}$ such that $\left\{G\left(Y_{m}\right)\right\}_{m} \geqslant 0$ is monotone and the following limit exists

$$
\lim _{m \rightarrow \infty} T\left(Y_{m}\right)=\lim _{m \rightarrow \infty} G\left(Y_{m}\right) \in X^{n} .
$$

From (3.12) and (3.13), we see that, for sequences $\left\{y_{m}^{1}\right\}_{m \geqslant 0},\left\{y_{m}^{2}\right\}_{m \geqslant 0}, \cdots,\left\{y_{m}^{n}\right\}_{m \geqslant 0} \subseteq X$ such that $\left\{g\left(y_{m}^{1}, \cdots, y_{m}^{k}\right)\right\}_{m \geqslant 0}, \cdots,\left\{g\left(y_{m}^{i k+1}, \cdots, u_{m}^{i k+k}\right)\right\}_{m \geqslant 0}, \cdots,\left\{g\left(y_{m}^{n-k+1}, \cdots, y_{m}^{n}\right)\right\}_{m} \geqslant 0$ are monotone and the following limit exists:

$$
\lim _{m \rightarrow \infty} F\left(y_{m}^{\sigma_{i+1}(1)}, y_{m}^{\sigma_{i+1}(2)}, \cdots, y_{m}^{\sigma_{i+1}(n)}\right)=\lim _{m \rightarrow \infty} g\left(y_{m}^{i k+1}, y_{m}^{i k+2}, \cdots, y_{m}^{i k+k}\right) \in X^{k}
$$

for $i \in\{0,1, \cdots, l-1\}$. Since $F$ and $g$ are $\Phi_{l}$-compatible, we have

$$
\begin{aligned}
\lim _{m \rightarrow \infty} M^{n}\left(G T\left(Y_{m}\right), T G\left(Y_{m}\right), t\right)= & \lim _{m \rightarrow \infty} *_{i=0}^{l-1} M^{k}\left(g F\left(y_{m}^{\sigma_{i+1}(1)}, \cdots, y_{m}^{\sigma_{i+1}(n)}\right),\right. \\
& \left.F\left(g\left(y_{m}^{\sigma_{i+1}(1)}, \ldots, y_{m}^{\sigma_{i+1}(k)}\right), \cdots, g\left(y_{m}^{\sigma_{i+1}(n-k+1)}, \cdots, y_{m}^{\sigma_{i+1}(n)}\right)\right), t\right)=1 .
\end{aligned}
$$

Therefore, $\mathrm{T}$ and $\mathrm{G}$ are compatible.

Now, we show that $T$ is a $G_{k}$-isotone mapping. Suppose that $G(Y) \preceq_{l} G(V)$ for $Y, V \in X^{n}$. By (2.1) and (3.13), we have $g\left(y_{j k+1}, \cdots, y_{j k+k}\right) \preceq g\left(v_{j k+1}, \cdots, v_{j k+k}\right)$ when $j+1 \in A$ and $g\left(y_{j k+1}, \cdots, y_{j k+k}\right) \succeq$ $g\left(v_{j k+1}, \cdots, v_{j k+k}\right)$ when $j+1 \in B$. For each $i+1 \in A$, we have $\sigma_{i+1} \in \Omega_{A B}$. So, for fixed $i+$ $1 \in A$, we have $g\left(y_{\sigma_{i+1}(j k+1)}, \cdots, y_{\sigma_{i+1}(j k+k)}\right) \preceq g\left(v_{\sigma_{i+1}(j k+1)}, \cdots, v_{\sigma_{i+1}(j k+k)}\right)$ when $j+1 \in A$ and 
$g\left(y_{\sigma_{i+1}(j k+1)}, \cdots, y_{\sigma_{i+1}(j k+k)}\right) \succeq g\left(v_{\sigma_{i+1}(j k+1)}, \cdots, v_{\sigma_{i+1}(j k+k)}\right)$ when $j+1 \in B$. Thus, by the mixed $g_{k^{-}}$ monotone property of $F$, for fixed $i+1 \in A$, we have

$$
\begin{aligned}
F\left(y_{\sigma_{i+1}(1)}, \cdots,\right. & \left.y_{\sigma_{i+1}(j k)}, y_{\sigma_{i+1}(j k+1)}, \cdots, y_{\sigma_{i+1}(j k+k)}, y_{\sigma_{i+1}(j k+k+1)}, \cdots, y_{\sigma_{i+1}(n)}\right) \\
& \preceq F\left(y_{\sigma_{i+1}(1)}, \cdots, y_{\sigma_{i+1}(j k)}, v_{\sigma_{i+1}(j k+1)}, \cdots, v_{\sigma_{i+1}}(j k+k)\right. \\
& \left.y_{\sigma_{i+1}(j k+k+1)}, \cdots, y_{\sigma_{i+1}(n)}\right),
\end{aligned}
$$

for $j+1 \in A$. Similarly, if $j+1 \in B$, then inequality (3.14) holds for fixed $i+1 \in A$. So, for fixed $i+1 \in A$, inequality (3.14) holds for all $j \in\{0,1, \cdots, l-1\}$. From this, we have

$$
\begin{aligned}
\mathrm{F}\left(\mathrm{y}_{\sigma_{i+1}(1)}, y_{\sigma_{i+1}(2)}, \cdots, y_{\sigma_{i+1}(n)}\right) & \preceq \mathrm{F}\left(v_{\sigma_{i+1}(1)}, \cdots, v_{\sigma_{i+1}(k)}, y_{\sigma_{i+1}(k+1)}, \cdots, y_{\sigma_{i+1}(n)}\right) \\
& \preceq \mathrm{F}\left(v_{\sigma_{i+1}(1)}, \cdots, v_{\sigma_{i+1}(2 k)}, y_{\sigma_{i+1}(2 k+1)}, \cdots, y_{\sigma_{i+1}(n)}\right) \\
& \preceq \cdots \\
& \preceq F\left(v_{\sigma_{i+1}(1)}, \cdots, v_{\sigma_{i+1}(n)}\right),
\end{aligned}
$$

for $i+1 \in A$. Similarly, we have

$$
F\left(y_{\sigma_{i+1}(1)}, y_{\sigma_{i+1}(2)}, \cdots, y_{\sigma_{i+1}(n)}\right) \succeq F\left(v_{\sigma_{i+1}(1)}, v_{\sigma_{i+1}(2)}, \cdots, v_{\sigma_{i+1}(n)}\right),
$$

for $i+1 \in$ B. Thus, by (3.12), (3.15), and (3.16), we deduce that $T$ is a $G_{k}$-isotone mapping.

The conditions (C7) and (C8) imply that (C3) and (C4) hold. It is easy to deduce that $\mathrm{T}$ and $\mathrm{G}$ are weakly compatible if assumption (C2) holds. If $F$ and $g$ are continuous, then $T$ and $G$ are continuous.

Given $G(Y) \preceq_{l} G(V)$, by Lemma 3.4, $\left(g\left(y_{\sigma_{i+1}(1)}, \cdots, y_{\sigma_{i+1}(k)}\right), \cdots, g\left(y_{\sigma_{i+1}(l k+1)}, \cdots, y_{\sigma_{i+1}(l k+k)}\right)\right)$ and $\left(\mathrm{g}\left(v_{\sigma_{i+1}(1)}, \cdots, v_{\sigma_{i+1}(k)}\right), \cdots, g\left(v_{\sigma_{i+1}(n-k+1)}, \cdots, v_{\sigma_{i+1}(n)}\right)\right)$ are comparable by $\preceq_{l}$. Therefore, (3.9) and (3.10) can be applied to these points, and it follows that for $t>0$,

$$
\begin{aligned}
M^{\mathrm{n}}(\mathrm{T}(\mathrm{Y}), \mathrm{T}(\mathrm{V}), \varphi(\mathrm{t})) & =*_{i=0}^{\mathrm{l}-1} M^{\mathrm{k}}\left(\mathrm{F}\left(\mathrm{y}_{\sigma_{i}(1)}, \cdots, y_{\sigma_{i}(\mathrm{n})}\right), \mathrm{F}\left(v_{\sigma_{i}(1)}, \cdots, v_{\sigma_{i}(\mathrm{n})}\right), \varphi(\mathrm{t})\right) \\
& \geqslant *_{i=0}^{l-1} \gamma\left(*_{j=0}^{l-1} M^{k}\left(g\left(y_{\sigma_{i}(j k+1)}, \cdots, y_{\sigma_{i}(j k+k)}\right), g\left(v_{\sigma_{i}(j k+1)}, \cdots, v_{\sigma_{i}(j k+k)}\right), \mathrm{t}\right)\right) \\
& \geqslant *_{i=0}^{l-1} \gamma\left(*_{j=0}^{l-1} M^{k}\left(g\left(y_{j k+1}, \cdots, y_{j k+k}\right), g\left(v_{j k+1}, \cdots, v_{j k+k}\right), t\right)\right) \\
& =*_{i=0}^{l-1} \gamma\left(M^{\mathrm{n}}(G(Y), G(V), t)\right)=*^{l} \gamma\left(M^{\mathrm{n}}(G(Y), G(V), t)\right) \\
& \geqslant M^{\mathrm{n}}(G(Y), G(V), t) .
\end{aligned}
$$

Next we shall prove that the condition (C2) holds. Since $g\left(X^{k}\right)$ is closed, so is $G\left(X^{n}\right)$. Suppose that $\left\{Z_{m}\right\}$ is non-decreasing sequence in $X^{n}$ such that $Z_{m} \rightarrow Z$ as $m \rightarrow \infty$. Using Lemma 3.3, we have $z_{m}^{i k+s} \rightarrow z^{i k+s}(m \rightarrow \infty)$ for $i+1 \in \Lambda_{n}$ and $s \in\{1,2, \cdots, s\}$. Since $Z_{m} \preceq_{l} Z_{m+1}$ for all $m \in \mathbb{N}_{0}$, then $\left(z_{m}^{i k+1}, \ldots, z_{m}^{i k+k}\right)_{m \in \mathbb{N}_{0}}$ is a non-decreasing sequence when $i+1 \in A$ and $\left(z_{m}^{i k+1}, \ldots, z_{m}^{i k+k}\right)_{m \in \mathbb{N}_{0}}$ is a non-decreasing sequence when $i+1 \in B$. If $i+1 \in A$, as $\left(X^{k}, \tau_{M^{k}}, \preceq\right)$ has the sequential monotone property, then we have $z_{m}^{i k+s} \preceq z^{i k+s}$ for all $m \in \mathbb{N}_{0}$ and $s \in\{1, \cdots, k\}$. Similarly, if $i+1 \in B$, then $\left(z_{m}^{i k+1}, \ldots, z_{m}^{i k+k}\right) \succeq\left(z^{i k+1}, \ldots, z^{i k+k}\right)$ for all $m \in \mathbb{N}_{0}$. That is, $Z_{m} \preceq_{l} Z$ for every $m \in \mathbb{N}_{0}$. The other case is treated similarly.

Therefore, all conditions of Theorems 3.6 and 3.7 hold. Theorem 3.6 implies that $T$ and $G$ have a coincidence point, which is a $\Upsilon_{k}$-coincidence point of $F$ and $g$. Moreover, it follows from Theorem 3.7 that $\mathrm{T}$ and $\mathrm{G}$ have a unique common fixed point, which is a unique common fixed point of $\mathrm{F}$ and $\mathrm{g}$.

\section{An example}

Example 4.1. Let $(X, \preceq)$ be the partially ordered set with $X=[0,1]$ and the natural ordering $\leqslant$ of the real numbers as the partially ordering $\preceq$. Define $M: X \times X \times \mathbb{R}^{+} \rightarrow \mathbb{I}$ by

$$
M(x, y, t)= \begin{cases}0, & t=0 \\ e^{-\frac{|x-y|}{t}}, & t>0\end{cases}
$$


Then $M(x, y, \cdot): \mathbb{R}^{+} \rightarrow \mathbb{I}$ is continuous. Let $x * y=\min \{x, y\}$ for $x, y \in X$. Then $(X, M, *)$ is complete FMS, which have been proved in [20]. By the same way, we define $\left(x_{1}, x_{2}\right) \preceq\left(y_{1}, y_{2}\right)$ if and only if $x_{1} \preceq y_{1}$ and $x_{2} \preceq y_{2}$. Then we have $\left(X^{2}, \preceq\right)$ is a partially ordered set. Consider $t, g: X \rightarrow X$ defined by $t(x)=\frac{x^{2}}{3}+\frac{2}{3}$ and $g(x)=x$. Let $T, G: X^{2} \rightarrow X^{2}$ define by $T\left(x_{1}, x_{2}\right)=\left(t\left(x_{1}\right), t\left(x_{2}\right)\right)$ and $G\left(x_{1}, x_{2}\right)=\left(g\left(x_{1}\right), g\left(x_{2}\right)\right)$.

It is easy to verify the following statements.

(i) $\mathrm{T}\left(\mathrm{X}^{2}\right) \subseteq \mathrm{G}\left(\mathrm{X}^{2}\right)$ and $\mathrm{T}$ is a $\mathrm{G}_{2}$-isotone mapping.

(ii) The condition (C1) holds.

(iii) There exists $\left(y_{1}, y_{2}\right)=(0,0)$ such that $G\left(y_{1}, y_{2}\right)=(0,0) \preceq\left(\frac{2}{3}, \frac{2}{3}\right)=T\left(Y_{0}\right)$.

Let $\left(y_{1}, y_{2}\right),\left(v_{1}, v_{2}\right) \in X^{2}$ such that $G\left(y_{1}, y_{2}\right) \preceq G\left(v_{1}, v_{2}\right)$, that is, $y_{1} \leqslant v_{1}$ and $y_{2} \leqslant v_{2}$.

Next, we show that the inequality (3.5) is satisfied with $\varphi(t)=\frac{3 t}{4}$ for $t>0$. If (3.5) does not hold, then there exists $t>0$ such that

$$
M^{2}\left(T\left(y_{1}, y_{2}\right), T\left(v_{1}, v_{2}\right), \frac{3 t}{4}\right)<M^{2}\left(G\left(y_{1}, y_{2}\right), G\left(v_{1}, v_{2}\right), t\right),
$$

that is,

$$
\min \left\{e^{-\left|\frac{y_{1}^{2}}{3}-\frac{v_{1}^{2}}{3}\right| / \frac{3 t}{4}}, e^{-\left|\frac{y_{2}^{2}}{3}-\frac{v_{2}^{2}}{3}\right| / \frac{3 t}{4}}\right\} \leqslant \min \left\{e^{-\left|y_{1}-v_{1}\right| / t}, e^{\left|y_{2}-v_{2}\right| / t}\right\}
$$

i.e.,

Since $y, v \in[0,1]$,

$$
\min \left\{\frac{4}{9}\left|y_{1}^{2}-v_{1}^{2}\right|, \frac{4}{9}\left|y_{2}^{2}-v_{2}^{2}\right|\right\}>\min \left\{\left|y_{1}-v_{1}\right|,\left|y_{2}-v_{2}\right|\right\}
$$

$$
|y-v|<\frac{4}{9}\left|y^{2}-v^{2}\right|=\frac{4}{9}|y-v|(y+v) \leqslant \frac{8}{9}|y-v|,
$$

which is impossible. Hence (3.5) holds. By Theorem 3.6, T and G have a unique common fixed point, which is $Z=(1,1)$.

Example 4.2. Let $X=\{0,0.25,0.5,1.5,1.75,2\}$ and $M: X \times X \times \mathbb{R}^{+} \rightarrow \mathbb{I}$ as follows:

$$
M(x, y, t)= \begin{cases}1, & |x-y|<t \\ \frac{t}{|x-y|+t}, & |x-y| \geqslant t .\end{cases}
$$

As Gregori et al. have pointed out in [6], any FMS $(X, M)$ is equivalent to Menger space in the sense that $M(x, y, t)=F_{x, y}(t)$ for all $x, y \in X$ and $t \geqslant 0$. Thus, $(X, M)$ is a complete FMS under $*=$ min.

Endow $X$ with the following partial order:

$$
x, y \in X, x \preceq y \Leftrightarrow x=y \text { or }(x, y) \in\{(0,0.5),(0,0.25)\} .
$$

Endow $X^{2}$ with the following partial order:

$$
\left(x_{1}, x_{2}\right),\left(y_{1}, y_{2}\right) \in X^{2} \text { or }\left(x_{1}, y_{1}\right),\left(x_{2}, y_{2}\right) \in\{(0,0.5),(0,0.25)\} .
$$

Let $\varphi: \mathbb{R}^{+} \rightarrow \mathbb{R}^{+}$be defined by

$$
\varphi(t)= \begin{cases}\frac{t}{1+t}, & 0 \leqslant t \leqslant 1 \\ -\frac{t}{3}+\frac{4}{3}, & 1<t \leqslant 2 \\ t-\frac{4}{3}, & 2<t<\infty .\end{cases}
$$

It is easy to see that $\varphi(t) \geqslant \frac{t}{1+t}$. Consider $f, g: X \rightarrow X$ defined by

$$
f(x)= \begin{cases}0, & x \in\{0,0.25,0.5,1.75,2\} \\ 0.25, & x=1.5\end{cases}
$$




$$
g(x)= \begin{cases}0, & x \in\{0,0.5\} \\ 0.5, & x=1.5 \\ 0.25, & x \in\{0.25,1.75,2\}\end{cases}
$$

$T\left(x_{1}, x_{2}\right)=\left(t\left(x_{1}\right), t\left(x_{2}\right)\right)$ and $G\left(y_{1}, y_{2}\right)=\left(g\left(y_{1}\right), g\left(y_{2}\right)\right)$. It is not difficult to prove the following statements.

(i) $\mathrm{T}\left(\mathrm{X}^{2}\right) \subseteq \mathrm{G}\left(\mathrm{X}^{2}\right)$.

(ii) The condition (C2) holds (Since $\tau_{M^{2}}$ is the discrete topology on $X^{2}$ ).

(iii) There exists $\left(y_{1}, y_{2}\right)=(0,0)$ such that $G\left(y_{1}, y_{2}\right)=\left(g\left(y_{1}\right), g\left(y_{2}\right)\right) \preceq\left(t\left(y_{1}\right), t\left(y_{2}\right)\right)=T\left(y_{1}, y_{2}\right)$ and $\lim _{t \rightarrow \infty} M^{2}\left(G\left(y_{1}, y_{2}\right), T\left(y_{1}, y_{2}\right), t\right)=1$.

(iv) All conditions of Theorem 3.7 hold.

In fact, $(0,0),(0.5,0.5),(0,0.5)$ and $(0.5,0)$ are all coincidence points of $T$ and $G$. Since $T\left(G\left(\overline{y_{1}}, \overline{y_{2}}\right)\right)=$ $\mathrm{GT}\left(\left(\overline{y_{1}}, \bar{y}_{2}\right)\right)$, where $\overline{y_{1}} \in\{0,0.5\}, \overline{y_{2}} \in\{0,0.5\}$, by Definition $2.11, G$ is weakly compatible with $T$. In addition, there exists $\left(u_{1}, u_{2}\right)=(1.5,1.5)$ such that $G\left(\overline{y_{1}}, \overline{y_{2}}\right) \leqslant G\left(u_{1}, u_{2}\right)$ and $G\left(\overline{y_{1}}{ }^{\prime}, \overline{y_{2}}{ }^{\prime}\right) \leqslant G\left(u_{1}, u_{2}\right)$. It follows from (4.1) and (C4) holds.

(v) $T$ is a $G_{2}$-isotone mapping. Indeed, let $\left(y_{1}, y_{2}\right),\left(v_{1}, v_{2}\right) \in X^{2}$ such that $G\left(y_{1}, y_{2}\right) \preceq G\left(v_{1}, v_{2}\right)$, i.e., $\mathrm{g}\left(\mathrm{y}_{1}\right) \preceq \mathrm{g}\left(v_{1}\right)$ and $\mathrm{g}\left(\mathrm{y}_{2}\right) \preceq \mathrm{g}\left(v_{2}\right)$.

(a) If $g(y)=g(v)$ then $y=v$ or $y, v \in\{0.25,1.75,2\},\{0,0.5\}$. Thus $t(y)=t(v)$. If $(g(y), g(v))=(0,0.25)$, then $y \in\{0,0.5\}, v \in\{0.25,1.75,2\}$. Thus $\mathrm{t}(\mathrm{y})=\mathrm{t}(v)$.

(b) If $(g(y), g(v))=(0,0.25)$, then $y \in\{0,0.5\}$ and $v \in\{0.25,1.75,2\}$. Thus $t(y)=t(v)$.

(c) If $(g(y), g(v))=(0,0.5)$, then, $y \in\{0,0.5\}$ and $v=1.5$. Thus $(t(y), t(v))=(0,0.25)$, i.e., $t(y) \preceq t(v)$.

Next, we shall prove that (3.5) holds. Let $\left(y_{1}, y_{2}\right),\left(v_{1}, v_{2}\right) \in X^{2}$ such that $G\left(y_{1}, y_{2}\right) \preceq G\left(v_{1}, v_{2}\right)$, i.e., $\mathrm{g}\left(\mathrm{y}_{1}\right) \preceq \mathrm{g}\left(v_{1}\right)$ and $\mathrm{g}\left(\mathrm{y}_{2}\right) \preceq \mathrm{g}\left(v_{2}\right)$. Wang [20] have proved that if $\mathrm{g}(\mathrm{y}) \preceq \mathrm{g}(v)$ holds, we obtain

$$
M(t(y), t(v), \varphi(t)) \geqslant M(g(y), g(v), t) .
$$

By $*=\min$, for $\mathrm{G}\left(\mathrm{y}_{1}, \mathrm{y}_{2}\right) \preceq \mathrm{G}\left(v_{1}, v_{2}\right)$, we obtain

$$
M^{2}\left(T\left(y_{1}, y_{2}\right), T\left(v_{1}, v_{2}\right), \varphi(t)\right) \geqslant M^{2}\left(G\left(y_{1}, y_{2}\right), G\left(v_{1}, v_{2}\right), t\right),
$$

which implies (3.5) holds.

By Theorem 3.7, $T$ and $G$ have a unique common fixed point, which is $Z=(0,0)$.

\section{Acknowledgment}

The authors would like to thank the editor and the referees for their constructive comments and suggestions. The research was supported by the Natural Science Foundation of China $(11361042,11071108$, 11461045,71363043), the Natural Science Foundation of Jiangxi Province of China (2010GZS0147,20114BAB 201003, 20142BAB211016, 20132BAB201001), and partly supported by the NSF of Education Department of Jiangxi Province of China (GJJ150008).

\section{References}

[1] B. S. Choudhury, K. Das, P. Das, Coupled coincidence point results for compatible mappings in partially ordered fuzzy metric spaces, Fuzzy Sets and Systems, 222 (2013), 84-97. 1

[2] L. Ćirić, Solving the Banach fixed point principle for nonlinear contractions in probabilistic metric spaces, Nonlinear Anal., 72 (2010), 2009-2018.1 
[3] J.-X. Fang, On $\varphi$-contractions in probabilistic and fuzzy metric spaces, Fuzzy Sets and Systems, 267 (2015), 86-99. 1

[4] A. George, P. Veeramani, On some results in fuzzy metric spaces, Fuzzy Sets and Systems, 64 (1994), 395-399. 2, 2

[5] T. Gnana Bhaskar, V. Lakshmikantham, Fixed point theorems in partially ordered metric spaces and applications, Nonlinear Anal., 65 (2006), 1379-1393. 1

[6] V. Gregori, S. Morillas, A. Sapena, On a class of completable fuzzy metric spaces, Fuzzy Sets and Systems, 161 (2010), 2193-2205. 4.2

[7] D. J. Guo, V. Lakshmikantham, Coupled fixed points of nonlinear operators with applications, Nonlinear Anal., 11 (1987), 623-632. 1

[8] X.-Q. Hu, Common coupled fixed point theorems for contractive mappings in fuzzy metric spaces, Fixed Point Theory Appl., 2011 (2011), 14 pages. 1

[9] X.-Q. Hu, M.-X. Zheng, B. Damjanović, X.-F. Shao, Common coupled fixed point theorems for weakly compatible mappings in fuzzy metric spaces, Fixed Point Theory Appl., 2013 (2013), 11 pages. 1

[10] J. Jachymski, On probabilistic ф-contractions on Menger spaces, Nonlinear Anal., 73 (2010), 2199-2203. 1

[11] J.-M. Jin, C.-X. Zhu, H.-C. Wu, New fixed point theorem for $\varphi$-contractions in KM-fuzzy metric spaces, J. Nonlinear Sci. Appl., 9 (2016), 6204-6209. 1, 2.15, 2.16

[12] E. Karapınar, A. Roldán, J. Martínez-Moreno, C. Roldán, Meir-Keeler type multidimensional fixed point theorems in partially ordered metric spaces, Abstr. Appl. Anal., 2013 (2013), 9 pages. 2

[13] I. Kramosil, J. Michálek, Fuzzy metrics and statistical metric spaces, Kybernetika (Prague), 11 (1975), 336-344 . 2.7

[14] A. Roldán, J. Martínez-Moreno, C. Roldán, Multidimensional fixed point theorems in partially ordered complete metric spaces, J. Math. Anal. Appl., 396 (2012), 536-545. 2, 2

[15] A. Roldán, J. Martínez-Moreno, C. Roldán, Y. J. Cho, Multidimensional coincidence point results for compatible mappings in partially ordered fuzzy metric spaces, Fuzzy Sets and Systems, 251 (2014), 71-82. 1, 2

[16] A. F. Roldán-López-de-Hierro, W. Sintunavarat, Common fixed point theorems in fuzzy metric spaces using the CLRg property, Fuzzy Sets and Systems, 282 (2016), 131-142. 3

[17] B. Schweizer, A. Sklar, Probabilistic metric spaces, North-Holland Series in Probability and Applied Mathematics, North-Holland Publishing Co., New York, (2005). 2.6

[18] S. Sedghi, I. Altun, N. Shobe, Coupled fixed point theorems for contractions in fuzzy metric spaces, Nonlinear Anal., 72 (2010), 1298-1304. 1

[19] S. Wang, Coincidence point theorems for G-isotone mappings in partially ordered metric spaces, Fixed Point Theory Appl., 2013 (2013), 13 pages. 2, 2, 2.3

[20] S. Wang, On $\varphi$-contractions in partially ordered fuzzy metric spaces, Fixed Point Theory Appl., 2015 (2015), 16 pages. $1,2,2.12,2,4.1,4.2$ 